\title{
The Effect of Family Life Education Training on Marital Satisfaction and Conflict Resolution Skills of Married Couples
}

\author{
T. Asha Jyothi*, M. Sarada Devi, P. Sridevi, R. Neela Rani and T. Supraja \\ College of Home Science, Professor Jayashankar Telangana State Agricultural University, \\ Saifabad, Hyderabad, India \\ *Corresponding author
}

\begin{abstract}
A B S T R A C T
\section{Keywords}

Family life education, Marital satisfaction,

Conflicts resolution skills and Married couple

Article Info

Accepted:

22 July 2020

Available Online:

10 August 2020

The purpose of this study was to determine the effectiveness of family life education training on marital satisfaction and marital conflicts in married couple. At this experimental study with pre-test-post-test design and one twenty sample were selected in Maheshrammandal, Telangana state, purposively selected for this study. First, the pre-test was administered for both men and women. The pre-test was consisted of a questionnaire on demographic information, marital satisfaction and marital conflicts. Then intervention was presented with ten 45-minute sessions on family life education training. At the end of trainings, which lasted for 6 weeks, both groups filled the questionnaires. The data were analysed using the SPSS and frequency, percentage and paired T-tests. The results showed that there was significant difference between marital satisfaction and reduction of marital conflicts of married couple. It can be concluded that family life education program had a positive and significant effect on the improve the marital satisfaction and reduces couples' marital conflict and it's components.

\section{Introduction}

Marriage continues to be an important social institution in India even in a time of changing social mores. Marriage is "not merely a set of social arrangements but also ideas, beliefs and values by which those arrangements are sustained" (Beteille, 1992). Traditionally, a marital union was regarded as perpetual and as an indissoluble sacrament in the cultural milieu of Indian society (Aura, 2008; Ramachandrappa, 2012). Marriages in India are not limited to the bond between the couple, but are perceived as a relationship

between two families which are brought together socially (Aura, 2008). However, modernising forces have altered the sociocultural fabric of India, influencing the structure, functioning and role expectations of familial and marital relationships (Madan, 1993; Singh, 2002; Sharangpani, 2010).

Marital satisfaction is a mental state that reflects the perceived benefits and costs of marriage to a particular person. It is a multidimensional concept that includes different factors such as personality features, financial matters, child rearing styles, and
\end{abstract}


sexual relations (Tazekand, et al., 2013). Enquiry on marital satisfaction and the factors that influence marital satisfaction is vast and covers many areas relating to this topic. Couple's agreement on the style of relation, emotions expression, sexual relation, leisure time activities, home duties sharing, duration of being beside each other, external network and supply and incompatible explanations can affect marital satisfaction (Vangelisti and Huston, 1994; Bradbury, et al., 1996).

Conflict is inevitable process in any marriage. The opposing needs and interests of the couples lie at the core of marital conflict. Conflict in general is described as the process that begins when one party perceives that the other one has frustrated some concerns of his/hers (Thomas, 1976) an interpersonal conflict exists whenever an action by one person prevents, obstructs or interferes with the actions of another person (Johnson 1990). In conflict situation, couples express or latent differences in satisfying their individual needs and interests, and they experience interference from their partners in accomplishing these goals. In the contemporary family, there is a great need to negotiate the changing role of husband and wife. Discussions about who makes the decisions and how they should be made create a great potential for marital conflict.

Marital conflict in itself is not necessarily bad. In fact, less emphasis should be placed on the number of conflicts experienced by a couple than on how they are managed and resolved. More specifically, Gottman and Levenson (1988) suggest that the manner in which a couple handle negative effect in a conflict determines whether the marriage succeeds or fails. The couple's skill in conflict resolution and the subsequent impact that such resolution has on each partner hold the key to whether the marriage continues to function in a constructive way or becomes a destructive or malfunctioning system. Hence in most interpersonal conflicts it is important to find a resolution.

Research reviews on people with marital conflicts and who had attended the marriage enrichment training through the PAIRS method can reduce marital conflicts. This method helps individuals improve their relationships and at the same time preserve the quality of these relationships over time. This approach is a training model to teach skills for the improvement of satisfaction and stability of couple relationship. (Mahshid Alsadat Keyhandoost, et al., (2017).

Stanly and Mockerman (2003) and Johnson and Cohen (2005) have also shown the positive effect of communication skill training and problem-solving on marital distress, controlling conflict, and marital satisfaction. Khojasteh Mehr (2008) argued that communication skills training can influence the positive emotions toward spouse. Emotionally focused therapy could reduce the rate of depression, anxiety and stress in couples and there were no significant differences between the two groups. (Mohammad Reza Shairi 2014).

Family Life Education is the practice of equipping and empowering family members to develop knowledge and skills that enhance well-being and strengthen interpersonal relationships through an educational, preventive, and strengths-based approach. It is the process of developing awareness and understanding of population situations as well as rational attitude and behavior towards those situations for the attainment of quality life for the family and the nation. Family life education is concerned with the study of attitudes and skills related to dating, marriage, parenting, family health and life of the family as a socio-cultural and economic unit in the society. 
The need for family life education subject is central to the holistic development of learners. One of the best ways used in improving the harmonious relationships between married couples is to teach them the basic communication and conflict resolution skills and help them to solve the conflicts in marriages in a health way (Fowers, 2001).

\section{Materials and Methods}

Married couple belonging to the age group of 18-38 years were selected for the study. Purposive sampling technique was adopted for the study. In the state of Telangana from Maheswaram Mandal Ramchandraguda and Dubbacherla villages were selected for the study. The sample for the study comprises of couple-both husband and wife. From two villages sixty (60) couples from each village were selected purposively. Thus, a total of one twenty (120) couples were selected purposively from two villages. To find out the marital satisfaction of married couple, the investigator used marital satisfaction dimension of social, emotional, interpersonal and sexual scale (Brinda Amritraj and Indira Jai Prakash, 1985) was used for pre and posttest to measure the effect of family life education on marital satisfaction. The data on marital satisfaction was collected in two stages one before and after intervention. The collected data was coded and analyzed using frequency, percentages and paired t-test (Table 1).

\section{Results and Discussion}

From table 2 it was evident that mean scores of marital satisfactions with respect to pre and post-test scores of interventions had shown significant differences in marital satisfaction. This intervention training significantly reduces marital conflicts and improves marital adjustments of married couple. These trainings had also significantly influenced the four aspects of marital satisfaction of married couple including social, emotional, interpersonal and sexual. The study revealed that the mean scores of marital satisfaction increased significantly after intervention. It can be concluded that the effect of intervention programme had positive effects on marital adjustment levels by improving communication.

The results of the study are in congruence with the study conducted by AzadehSoltani (2013) studied on the Effectiveness of Emotional Focused Couple Therapy on Intimacy of Couples. Study results revealed that here is a significant difference between the two groups in intimacy. Further results showed that EFCT increased emotional, psychological, sexual, physical, relationship, temporal and intellectual intimacy between the two groups. Another study which is in line with the results of the study conducted by Maryam Zarnaghash (2013) studied on influence of family therapy on marital conflicts. This study results revealed that family therapy has significant influence on solving of marital problems especial communication problems between couple also family therapy decreased individual conflicts in women.

From the table 3, it was found that there was a significant relationship between pre and posttest scores in problem solving skills of married couple. The $t$ test results showed that there was a significant difference in married couples after intervention in all domains such as physical, emotional, interpersonal, family and financial domains.

The high mean score of conflict resolving skills components indicates that married couples were better ability to resolve their conflicts and improved communication patterns. It can be concluded that intervention programme had positive effective in reducing 
marital conflicts as well as proper communication skills increases marital satisfaction.

The results were further supported by Mazhari et al., (2016) study on the effect of relationship enhancement program (REP) on reducing marital conflicts of dual- career couples. The sessions of relationship enhancement program were held in 8 sessions in groups for the experiment group, but the control group did not receive any intervention (Fig. 1 and 2).

Table.1 Framework of the training sessions

\begin{tabular}{|c|c|}
\hline $\begin{array}{l}\text { 1. Effective communication } \\
\text { and intimacy }\end{array}$ & $\begin{array}{l}\text { 1.Describing effective interpersonal communications and the } \\
\text { ways for their creation } \\
\text { 2. Explaining the concept of intimacy and its dimensions } \\
\text { 3.Adopting ways to establish intimacy } \\
\text { 4.Implementing practical techniques for creating intimacy }\end{array}$ \\
\hline $\begin{array}{l}\text { 2. Couples' conflict and } \\
\text { conflict resolution }\end{array}$ & $\begin{array}{l}\text { 1.The concept of conflict in marital relationships and } \\
\text { understanding its naturalness } \\
\text { 2. Identifying the barriers to conflict resolution } \\
\text { 3- correct roles and principles of conflict resolution } \\
\text { 4- implementing the practical techniques of conflict resolution }\end{array}$ \\
\hline 3. Problem solving skills & $\begin{array}{l}\text { 1.Defining the problem-solving process } \\
\text { 2. Teaching the steps of problem-solving process } \\
\text { 3. Implementing the practical techniques of problem-solving. }\end{array}$ \\
\hline 4. Empathy & $\begin{array}{l}\text { 1. Concept of empathy and understanding its naturalness. } \\
\text { 2. Enhancing empathy active listening, verbal and non-verbal } \\
\text { models and }\end{array}$ \\
\hline 5. Decision making skills & $\begin{array}{l}\text { 1. Teaching the importance of accepting the spouse and involving } \\
\text { partners in decision-making and respecting } \\
\text { 2. his/her opinions and feelings, exercising to investigate the } \\
\text { forms of men's resistance to be involved in decision-making } \\
\text { 3. with their wives, measures to enhance the emotional feelings, } \\
\text { and acceptance of surrender. }\end{array}$ \\
\hline
\end{tabular}

Table. 2 Mean differences in marital satisfaction among married couples pre and post intervention

\begin{tabular}{|c|l|c|c|c|c|c|c|}
\hline \multirow{2}{*}{ S. No } & \multicolumn{1}{|c|}{ Dimensions } & \multicolumn{2}{|c|}{ Pre-test } & \multicolumn{2}{c|}{ Post-test } & t-value & p-value \\
\cline { 3 - 8 } & & Mean & SD & Mean & SD & & \\
\hline 1. & Social & 6.43 & 2.3 & 8.43 & 3.5 & -9.23 & $0.000^{* * *}$ \\
\hline $\mathbf{2 .}$ & Emotional & 7.15 & 3.3 & 8.11 & 3.6 & -2.88 & $0.004 * *$ \\
\hline $\mathbf{3 .}$ & Interpersonal Relations & 5.96 & 1.8 & 8.56 & 3.3 & -11.9 & $0.000^{* * *}$ \\
\hline $\mathbf{4 .}$ & Sexual & 6.96 & 2.0 & 7.66 & 1.9 & -2.48 & $0.014 *$ \\
\hline $\mathbf{5 .}$ & Total scores & 25.39 & 6.5 & 32.70 & 8.1 & -15.19 & $0.000^{* * *}$ \\
\hline
\end{tabular}


Table.3 Mean differences in problem solving skills among married couples before and after intervention

\begin{tabular}{|c|l|c|c|c|c|c|c|}
\hline S.No. & \multirow{2}{*}{ Problem Solving Skills } & \multicolumn{2}{|c|}{ Pre } & \multicolumn{2}{c|}{ Post } & t-value & P - \\
\cline { 3 - 8 } & & Mean & SD & Mean & SD & & value \\
\hline $\mathbf{1}$ & Physical Domain & 21.3 & 7.1 & 24.3 & 9.1 & -3.1 & $0.001^{* *}$ \\
\hline $\mathbf{2}$ & Emotional Domain & 24.49 & 7.7 & 27.6 & 10.3 & -2.5 & $0.01^{*}$ \\
\hline $\mathbf{3}$ & Family Domain & 24.15 & 8.7 & 27.8 & 9.4 & -2.9 & $0.004^{* *}$ \\
\hline $\mathbf{4}$ & Financial Domain & 24.4 & 9.08 & 28.15 & 9.4 & -3.2 & $0.001^{* *}$ \\
\hline $\mathbf{5}$ & Academic and Career Domain & 22.53 & 7.2 & 25.09 & 9.2 & -2.4 & $0.01^{*}$ \\
\hline $\mathbf{6}$ & Interpersonal relationships & 23.78 & 8.2 & 28.15 & 10.4 & -3.1 & $0.002^{* *}$ \\
\hline & Total & 146.1 & 21.5 & 157.5 & 29.5 & -3.2 & $0.001^{* *}$ \\
\hline
\end{tabular}

Note: *Significance at $(\mathrm{P}<0.05), * *$ Significance at $(\mathrm{P}<0.05)$, NS- Not Significant

Fig.1 Mean differences in marital satisfaction of married couples before and after intervention

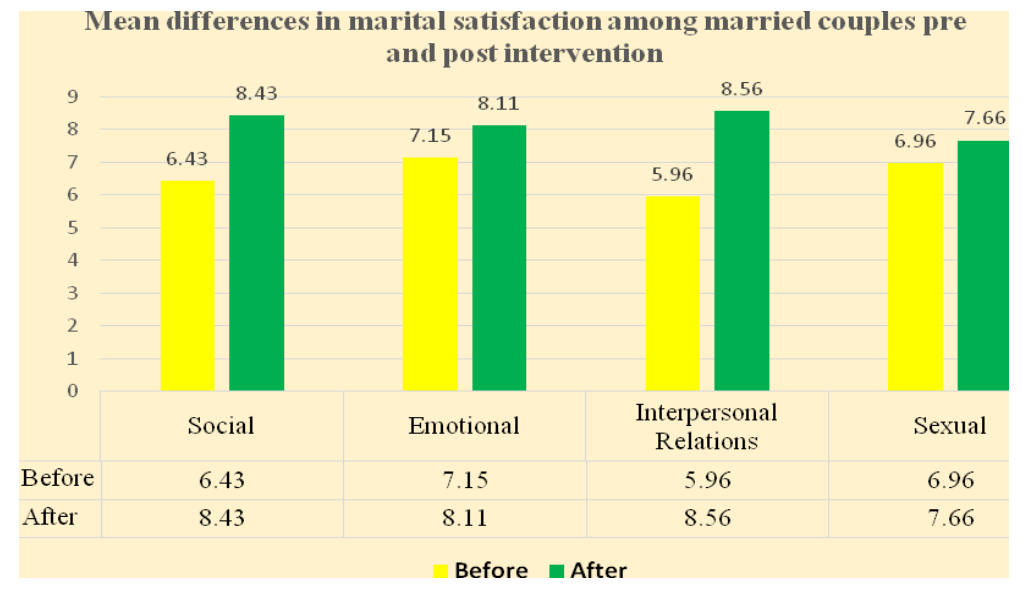

Fig.2

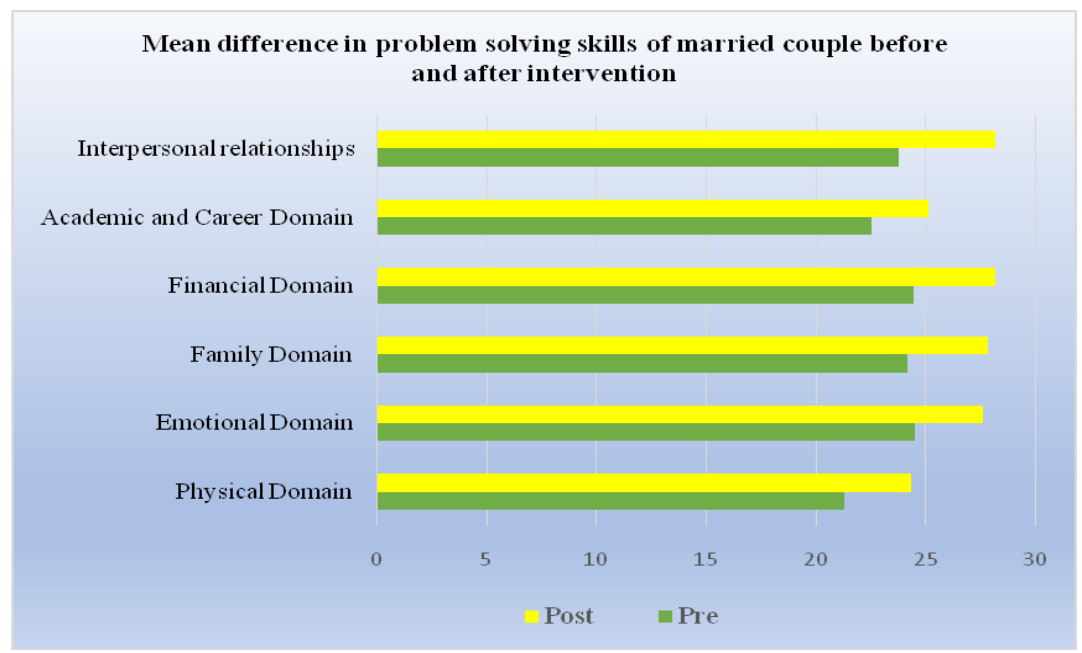


The results showed that the training of relationship enhancement program (REP) has led to significant decrease in marital conflicts among the women of the experiment group in the post-test stage $(\mathrm{F}=13.92$ and $\mathrm{P}<0.01)$, and it has led to significant decrease in all the components of this variable, as well; including reduction of cooperation, reduction of sexual relationship, increased emotional reactions, increase in drawing child's support, increased personal relationship with relatives, reduction of family relationship with relatives of spouse and friends, and separating financial matters from each other. Elham Mohammadi et al., (2016) study on Effectiveness of Acceptance and Commitment Therapy (ACT) on Depression in Women with Marital Conflicts. showed a significant reduction of depression at the post-test and follow-up stage $(\mathrm{P}<0.002)$.

In conclusion the aim of this study was to evaluate the effect of family life education on marital satisfaction and problem-solving skills of married couple. The results of the study showed that family life education training had a positive and significant effect on the marital satisfaction of married couple and this intervention helped the couple in positive emotions and the ability to reduce negative emotions when solving conflicts. The findings of the study revealed that family life education programme led to changes in marital adjustments and reduced the marital conflicts of couples.

\section{References}

Addisu Tegegn Bayle, Dereje Wonde Ayalew and Asabneh Molla Yimer (2017) Socio-demographic determinants of marital satisfaction in Jimma Zone, Southwest Ethiopia. International Journal of Sociology and Anthropology; 9(10); 131-142, doi: 10.5897/IJSA2016.0689.
Aura, Siru (2008). Women and Marital Breakdown in South India: Reconstructing Homes, Bonds and Persons. Finland: University of Helsinki.

AzadehSoltani, Javad Molazadehb et al., (2013) Effectiveness of Emotional Focused Couple Therapy on Intimacy of Couples. Procedia - Social and Behavioral Sciences 82 ( 2013 ) 461 465 1877-0428

Beteille, Andre (1992). Caste and Family in Representations of Indian Society. Anthropology Today, 8 (1): 13-18.

Gottman, J. M., and Levenson, R. W., 1988. The social psychophysiology of marriage. In P. Noller\& M. A. Fitzpatrick (Eds.), Perspectives on markal interaction Philadelphia, PA: Mukilingual Matters Ltd.

https://www.ncfr.org/cfle-certification/whatfamily-life-education

Johnson, D. W. 1990, Culture and the development of conflict resolution style. J. Cross Cultural Psychol, 13(1): 43-58.

Johnson, Matthew, D, Cohan, Catherinel. (2005). Problem solving skills and affective expressions as predictors of change in marital satisfaction, Journal of consulting and clinical psychology, 73, 15-27.

Khojastemehr, R., Y. Attari and K. Shiraninia. (2007). The effect of communication skills on communication patterns and positive feeling toward the spouse in the couples of Ahwaz City. J. Counseling Novelties and Res, 27, 81-97.

Madan, T (1993). The Hindu Family and Development. In $\mathrm{P}$ Uberoi (ed), Family, Kinship and Marriage in India. Delhi: Oxford University Press. Mahshid Alsadat Keyhandoost and Ebrahim Namani (2017) Study on the Effectiveness of Marriage Enrichment 
Training through PAIRS Method in Marital Conflicts. Social Sciences and Humanities, Advances in Applied Sociology; 7 , 172-180, http://www.scirp.org/journal/aasoci ISSN Online: 2165-4336, ISSN Print: 2165-4328

Maryam Zarnaghash, Mina Zarnaghash and Razieh Shahni (2013) The influence of family therapy on marital conflicts. Procedia - Social and Behavioural Sciences; 84:1838-1844

Mazhari, M, K Zahrakar, M Shakarami, R Davarniya and AAbdollah Zadeh (2016) The Effect of Relationship Enhancement Program (REP) on Reducing Marital Conflicts of DualCareer Couples. Iran Journal of Nursing; 29(102): 32-44.doi: 10.29252/ijn.29.102.32

Sharangpani, M (2010). Browsing for Bridegroom: Matchmaking and
Modernity in Mumbai. Indian Journal of Gender Studies, 17 (2): 249-76.

Stanley SM, Markman H.J. (2003). Facts about marital distress and divorce. Denver ; university of Denver ; : 91 95

Stephanie Whitson and Mona El-Sheikh (2003) Marital conflict and health: Processes and protective factors. Aggression and Violent Behavior 8(3):283-312. DOI: $10.1016 / \mathrm{S} 1359-$ 1789(01)00067-2

Tazekand S, Nafarb G, Keramati T (2013). The relationship between marital satisfaction and job satisfaction among employees of Social Welfare Organization at Tehran Branches. Life Sci. J. 10(6s).

Thomas, K. W., 1976, Conflict and conflict management. M. Dunnett (Ed.), Handbook of industrial and organizational psychol, 889-935.

\section{How to cite this article:}

Asha Jyothi, T., M. Sarada Devi, P. Sridevi, R. Neela Rani and Supraja, T. 2020. The Effect of Family Life Education Training on Marital Satisfaction and Conflict Resolution Skills of Married Couples. Int.J.Curr.Microbiol.App.Sci. 9(08): 2917-2923. doi: https://doi.org/10.20546/ijcmas.2020.908.326 